\title{
Internet Traffic Distribution Analysis in case of Multi-Operator and Multi-Market Environment of Computer Network
}

\author{
Sharad Gangele, PhD \\ Associate Professor \\ Dept. of Computer Science \\ RKDF University, Bhopal M. P., India
}

\author{
Sunil Patil \\ Assistant Professor \\ Dept. of Computer Science \& Engineering, \\ Vedica Institute of Technology, RKDF University, \\ Bhopal, M. P., India
}

\begin{abstract}
Internet is widely used across the world to serve many purposes by millions of people every minute. This has given rise to many fold increase in internet based service providers. The internet traffic shared between these service providers gets jammed due to heavy load on the network. Naldi (2002) discussed model based internet traffic share problem in a different way, based on the assumption of call-by-call basis. Further, this idea of call-by-call improved and transformed to two-call-basis by Shukla and Gadewar (2010) and enhanced results arrived. In this paper market based internet traffic share has been calculated in terms of quality of services, initial preferences and other network parameters. Traffic share expressions for different kind of operators have been derived and simulation study is performed. It is found that traffic share is highly correlated with the location of market and network blocking probability.
\end{abstract}

\section{Keywords}

Traffic Share Analysis (TSA), Two Call Basis (TCB), Transition Probability Matrix (TPM), Markov Chain Model (MCM)

\section{INTRODUCTION}

Here a situation is assumed where two prime markets exist. Each market has an internet café with connection of two operators. Each operator of both markets has placed its services on the internet such that a customer can visit the services online to find a suitable one matching his choice. A user has a choice to pickup one market suiting his requirements and then selects an operator of his choice. Since it is quite possible that at a single point of time there could be millions of people searching the same service from an operator and results in definite jamming of internet traffic. Internet traffic being in distributed nature, there is no single point of measurement for total traffic on the internet. Due to this difficulty of non-availability of tools to measure the total traffic, it turns to network blocking of both operators. Hence the matter of interest is to know how blocking probability affects the customer proportion in the setup of two markets. Naldi (2002) opened up model based internet traffic share problem in a new frame work. Network blocking probability for each operator is according to their quality of services. Markov chain model has been used and traffic share expressions for different operators have been derived. At the same time Simulation methodology is applied to calculate supporting results.

\section{LITERATURE REVIEW}

Park and Willinger (2000) discuss self and similar network traffic and calculate performance evaluation on it. Naldi(2002) gives internet traffic sharing problem in a multioperator environment case in a different look. Medhi(1992) presents a detail description of stochastic processes and random walk in real life situation. Altman, Avrachenkov and Brakat (2002) suggested a case study of large delaybandwidth product in TCP network. Antal, Molnar and Szabo (1998) presents a performance study of distributed channel allocation techniques for a fast circuit switched network. Catledge and Pitkow (1995) studied some browsing strategies in a new look on World Wide level. Newby and $\operatorname{Dagg}(2002)$ focused on optical inspection and maintenance for stochastically deteriorating systems in special case for average cost criteria. Shukla and Gadewar(2007) initiated a stochastic model for cell movement in a Knockout Switch and presented a probability based results on it. Agarwal and Kaur (2008) performed reliability analysis for fault-tolerance in multistage interconnection networks case. Shukla et al.(2007) utilized markov chain model as a tool for space-division switching in a computer network. Naldi(1999) attempt for measurement based modelling of internet dial-up access connections and develop some new result.Shukla et al.(2007) explain a stochastic model for space-division switches in computer networks where as Shukla et al.(2010) conducted a study on cyber crime based traffic share analysis for the judgment of users behavior. Shukla and Thakur (2009) have given a new view point approach on state probability analysis of users in internet in case of two operators environments. Shukla and Gadewar (2010) discuss a two call based markov chain model for traffic share problem while Shukla and Singhai(2011) have given a useful contribution on analysis of user web browsing behaviour by using markov chain model.Shukla,Gangele, Singhai,Verma(2011) have descrived elasticity analysis of web-browsing behaviour of users and find some new results. One more contribution is due to Shukla et al.(2010) on curve fitting approximation in internet traffic distribution in computer network in two market environment. Gangele and Shukla (2014) have used numerical analysis technique for area computation in internet traffic share problem with special reference to cyber crime environment. Gangele and Dongre (2014) analysed probability density estimation function of browser share curve for the study of users web browsing behavior. Gangele and Dongre(2014) have given a mathematical approach on two-call index based internet traffic sharing analysis in case of cyber crime environment. Gangele (2014) has put on a new look on an approach for area estimation towards conjunction control of internet traffic sharing by using Simpson 1/3ed rule. Shukla et 
al.(2015) have innovatively presented approximating the probability of traffic sharing by numerical analysis techniques between two operators in a computer network. Shukla et al. ( 2015) have proposed a novel approach on bounded area estimation using Simpson 3/8 rule in traffic share scenario and develop a procedure for it.

\section{MARKOV CHAIN MODEL AND USER'S BEHAVIOUR}

Let $O_{i}$ and $O_{j}(\mathrm{i}=1,3 ; \mathrm{j}=2,4)$ be operators (ISP) in the two competitive market, Market-I and Market-II respectively. Users choose first a market, and then enter into a Cyber-Café situated therein. Where computer terminals of different operators are available to access the internet.

Let $\left\{Y^{(n)}, n \geq 0\right\}$ be a Markov Chain having transitions over the State Space $\left\{\mathrm{M}_{1}, \mathrm{M}_{2}, \mathrm{O}_{1}, \mathrm{O}_{2}, \mathrm{O}_{3}, \mathrm{O}_{4}, \mathrm{Z}_{1}, \mathrm{Z}_{2}\right.$ and $\left.\mathrm{A}\right\}$

State $\mathbf{M}_{1}$ : Market-I

State $\mathbf{M}_{2}$ : Market-II

State $\boldsymbol{O}_{\mathbf{1}}$ : First operator in Market-I

State $\boldsymbol{O}_{2}:$ Second operator in Market-I

State $\boldsymbol{O}_{3}:$ Third operator in Market-II

State $\boldsymbol{O}_{4}:$ Fourth operator in Market-II

State $\boldsymbol{Z}_{\mathbf{1}}$ : Success (link) in Market-I $\left(M_{1}\right)$

State $\boldsymbol{Z}_{\mathbf{2}}$ : Success (link) in Market-II $\left(M_{2}\right)$

State A : Abandon to call attempt process

The $Y^{(n)}$ stands for the State of random variable $\mathrm{Y}$ at $n^{(t h)}$ attempt of Connectivity $(n \geq 0)$ made by the user. Some under line assumptions of the model are:

a) A user (or customer) first selects the Market-I with probability q and Market-II with probability (1-q).

b) After choosing a market, user in Cyber-Café (shop), choose the first operator $O_{i}(i=1,3)$ with probability $\mathrm{p}$ and $O_{j}(j=2,4)$ with probability $(1-\mathrm{p})$.

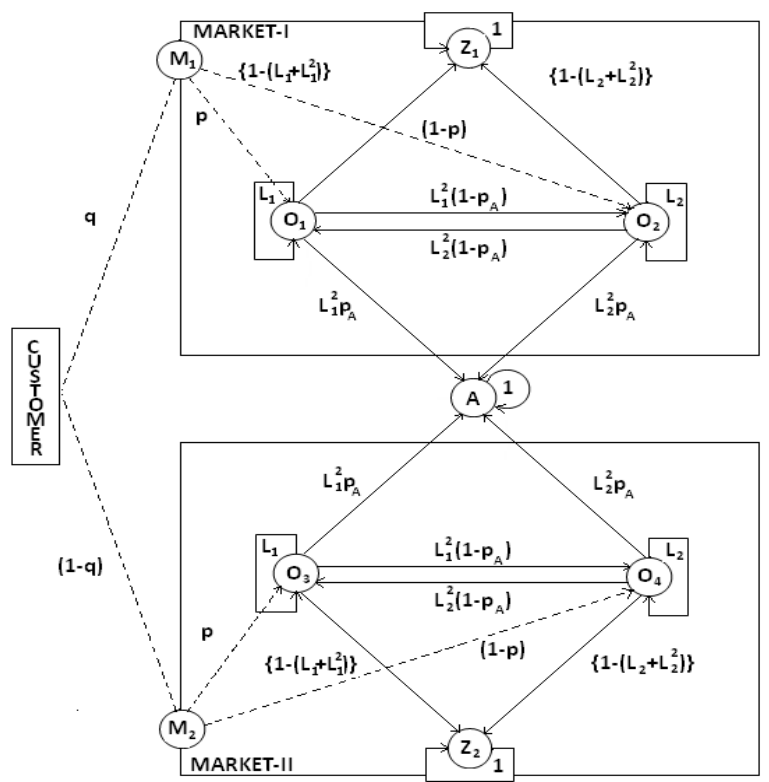

Fig. 3.1: Transition Diagram of Model c) The blocking probability experienced by the $O_{i}(i=1,3)$ is $L_{1}$ and $O_{j}(j=2,4)$ is $L_{2}$.

d) The Connectivity attempts by user between operators are on two-call basis, i.e. when first attempt of connectivity is failed, the user attempts one more to the same operator, and thereafter, switch over to the next one where two more consecutive attempts are likely.

e) Whenever call connects through either of operator $O_{i}$ $(i=1,3)$ or $O_{j}(j=2,4)$ we say system reaches to the state of success $\left(\mathrm{Z}_{1}, \mathrm{Z}_{2}\right)$ respectively in $n^{(t h)}$ attempt.

f) User can terminate the attempt process, which is marked as system to abandon State $\mathrm{A}$ with probability $p_{A}$ (either from $O_{i}(i=1,3)$ or from $\left.O_{j}(j=2,4)\right)$.

\begin{tabular}{|c|c|c|c|c|c|c|c|c|}
\hline & $o_{1}$ & $\mathrm{O}_{2}$ & $O_{3}$ & $O_{4}$ & $Z_{1}$ & $Z_{2}$ & $A$ & $M_{1} M_{2}$ \\
\hline $0_{1}$ & $L_{1}$ & $L_{1}^{2}\left(1-p_{A}\right)$ & 0 & 0 & $\left\{1-\left(L_{1}+L_{1}^{2}\right)\right\}$ & 0 & $L_{1}^{2} p_{A}$ & 0 \\
\hline $\mathrm{O}_{2}$ & $L_{2}^{2}\left(-p_{A}\right)$ & $L_{2}$ & 0 & 0 & $\left\{1-\left(L_{2}+L_{2}^{2}\right)\right\}$ & 0 & $L_{2}^{2} p_{A}$ & 0 \\
\hline$O_{3}$ & 0 & 0 & $L_{1}$ & $L_{1}^{2}\left(1-p_{A}\right)$ & 0 & $\left\{1-\left(L_{1}+L_{1}^{2}\right)\right\}$ & $L_{1}^{2} p_{A}$ & 0 \\
\hline $0_{4}$ & 0 & 0 & $L_{2}^{2}\left(1-p_{A}\right)$ & $L_{2}$ & 0 & $\left\{1-\left(L_{2}+L_{2}^{2}\right)\right\}$ & $L_{2}^{2} p_{A}$ & 0 \\
\hline$Z_{1}$ & 0 & 0 & 0 & 0 & 1 & 0 & 0 & 0 \\
\hline$Z_{2}$ & 0 & 0 & 0 & 0 & 0 & 1 & 0 & 0 \\
\hline$A$ & 0 & 0 & 0 & 0 & 0 & 0 & 1 & 0 \\
\hline$M_{1}$ & $\mathrm{p}$ & 1-p & 0 & 0 & 0 & 0 & 0 & 0 \\
\hline$M_{2}$ & 0 & 0 & $\mathrm{p}$ & 1-p & 0 & 0 & 0 & 0 \\
\hline
\end{tabular}

Fig. 3.2: Transition Probability Matrix

\section{LOGIC FOR TRANSITION MECHANISM IN MODEL AND PROBABILITY}

There are some certain rules for transition mechanism in model for market-I.

Rule 1:

The starting Conditions (State distribution before the first call attempt) are:

$\mathrm{P}\left[\mathrm{Y}^{(0)}=\mathrm{O}_{1}\right]=0 \& \mathrm{P}\left[\mathrm{Y}^{(0)}=\mathrm{O}_{2}\right]=0$

$\mathrm{P}\left[\mathrm{Y}^{(0)}=\mathrm{Z}_{1}\right]=0 \quad \& \mathrm{P}\left[\mathrm{Y}^{(0)}=\mathrm{Z}_{2}\right]=0$

$\mathrm{P}\left[\mathrm{Y}^{(0)}=\mathrm{M}_{1}\right]=\mathrm{q} \quad \& \mathrm{P}\left[\mathrm{Y}^{(0)}=\mathrm{M}_{2}\right]=1-\mathrm{q}$

Rule 2:

User attempts to operator $\mathrm{O}_{\mathrm{i}}(i=1,3)$ or $\mathrm{Oj}(j=2,4)$ with initial probabilities $\mathrm{p}$ (based on quality of service).

Rule 3:

If users (customers) fail in connectivity in first attempt then reattempt to operator $\mathrm{O}_{1}$.

Rule 4:

User may succeed to $\mathrm{O}_{1}$ in one attempt or in the next. Since the blocking probabilities for $\mathrm{O}_{1}$ in the attempt is $\mathrm{L}_{1}$, therefore blocking probabilities for $\mathrm{O}_{1}$ in the next attempt is

$=P\left[O_{1}\right.$ Blocked in an attempt $] P\left[O_{1}\right.$ blocked in next attempt $/$ previous attempt to $O_{1}$ was blocked]

$=\left(\mathrm{L}_{1} \mathrm{~L}_{1}\right)=\mathrm{L}_{1}^{2}$

The total blocking probabilities is $\left(L_{l}+L_{l}^{2}\right)$ is inclusive of both attempts. 
Hence success probability for $O_{1}$ is $\left[1-\left(L_{l}+L_{1}^{2}\right)\right]$. Similarly could be derived for operator $\mathrm{O}_{2}$ in form $\left[1-\left(L_{2}+L_{2}{ }^{2}\right)\right]$.

\section{Rule 5:}

User shift to $\mathrm{O}_{2}$ if call blocked in both attempts to $\mathrm{O}_{1}$ and does not abandon the attempting process.

The transition probability is $=P\left[O_{1}\right.$ blocked in an attempt $] . P$ $\left[O_{1}\right.$ blocked in next attempt/previous attempt to $O_{1}$ was blocked].P[ does not abandon attempting process ]

$=L_{1}^{2}\left(1-p_{A}\right)$

\section{Rule 6:}

User earliest abandons the system only after two attempts to an operator which is a compulsive assumption with this model. This leads to probabilities that user abandons process after two attempts over $\mathrm{O}_{1}$ is

$=P\left[O_{l}\right.$ blocked in attempt]. $P\left[O_{l}\right.$ blocked in next attempt $/$ Previous attempt to $O_{I}$ was blocked].P [abandon the attempting process]

$=\mathrm{L}_{1}^{2} \mathrm{p}_{\mathrm{A}}$

Similarly can be explained for operator $\mathrm{O}_{2}, \mathrm{O}_{3}$ and $\mathrm{O}_{4}$ for Market-I and Market- II respectively.

\section{SOME RESULTS FOR $\mathbf{n}^{\text {th }}$ CONNECTIVITY ATTEMPTS}

In $\mathrm{n}^{\text {th }}$ attempt the probability of resulting state is derived in the following forms for all $\mathrm{n}=0,1,2,3 \ldots$ for Market-I. If the user make attempt between $\mathrm{O}_{\mathrm{i}}(i=1,3)$ and $\mathrm{O}_{\mathrm{j}}(j=2,4)$ then the $\mathrm{n}^{\text {th }}$ step transitions probability is

$$
\begin{aligned}
& \mathrm{P}\left[\mathrm{y}^{(0)}=0_{1}\right]=\mathrm{P}\left[\mathrm{y}^{(0)}=0_{3}\right]=\mathrm{p} \text { and } \\
& \mathrm{P}\left[\mathrm{y}^{(0)}=0_{2}\right]=\mathrm{P}\left[\mathrm{y}^{(0)}=0_{4}\right]=(1-\mathrm{p})
\end{aligned}
$$

The detail of transition probabilities for $\mathrm{n}>0$ are given in the above for the attempts $n=0,1,2,3 \ldots$ classified into four different categories. The general expression of probability of $\mathrm{n}^{\text {th }}$ attempt for $\mathrm{O}_{\mathrm{i}}(i=1,3)$ and $\mathrm{O}_{\mathrm{j}}(j=2,4)$ defined below.

\section{$5.1 \mathrm{n}^{\text {th }}$ CONNECTIVITY ATTEMPTS FOR}

\section{MARKET-I}

Type A: When $t=4 n+1$

$$
\begin{aligned}
& P\left[Y^{(4 n+1)}=O_{1}\right]_{A}^{M_{1}}=\left[q p L_{1}^{3 n+1} L_{2}^{3 n}\left(1-p_{A}\right)^{2 n}\right] \\
& P\left[Y^{(4 n+1)}=O_{2}\right]_{A}^{M_{1}}=\left[q(1-p) L_{1}^{3 n} L_{2}^{3 n+1}\left(1-p_{A}\right)^{2 n}\right] \\
& P\left[Y^{(4 n+1)}=O_{2}\right]_{A}^{M_{1}}=\left[q(1-p) L_{1}^{3 n} L_{2}^{3 n+1}\left(1-p_{A}\right)^{2 n}\right]
\end{aligned}
$$

Type B: When $t=4 n-1$

$$
\begin{aligned}
& P\left[Y^{(4 n-1)}=1\right]_{B}^{M_{1}}=\left[q(1-p) L_{1}^{3 n-2} L_{2}^{3 n}\left(1-p_{A}\right)^{2 n-1}\right] \\
& P\left[Y^{(4 n-1)}=O_{2}\right]_{B}^{M_{1}}=\left[q p L_{1}^{3 n+1} L_{2}^{3 n-2}\left(1-p_{A}\right)^{2 n-1}\right]
\end{aligned}
$$

Type C: When $t=4 n$

$$
P\left[Y^{(4 n)}=O_{1}\right]_{C}^{M_{1}}=\left[q p L_{1}^{3 n} L_{2}^{3 n}\left(1-p_{A}\right)^{2 n}\right]
$$

$P\left[Y^{(4 n)}=O_{2}\right]_{C}^{M_{1}}=\left[q(1-p) L_{1}^{3 n} L_{2}^{3 n}\left(1-p_{A}\right)^{2 n}\right]$

Type D: When $t=4 n-2$

$$
\begin{aligned}
& P\left[Y^{(4 n-2)}=O_{1}\right]_{D}^{M_{1}}=\left[q(1-p) L_{1}^{3 n-3} L_{2}^{3 n}\left(1-p_{A}\right)^{2 n-1}\right] \\
& P\left[Y^{(4 n-2)}=O_{2}\right]_{D}^{M_{1}}=\left[q p L_{1}^{3 n} L_{2}^{3 n-3}\left(1-p_{A}\right)^{2 n-1}\right]
\end{aligned}
$$

\section{$5.1 n^{\text {th }}$ CONNECTIVITY ATTEMPTS FOR MARKET-II}

Type A: When $t=4 n+1$

$$
\begin{aligned}
& P\left[Y^{(4 n+1)}=O_{3}\right]_{A}^{M_{2}}=\left[(1-q) p L_{1}^{3 n+1} L_{2}^{3 n}\left(1-p_{A}\right)^{2 n}\right] \\
& P\left[Y^{(4 n+1)}=O_{4}\right]_{A}^{M_{2}}=\left[(1-q)(1-p) L_{1}^{3 n} L_{2}^{3 n+1}\left(1-p_{A}\right)^{2 n}\right]
\end{aligned}
$$

Type B: When $t=4 n-1$

$$
\begin{aligned}
& P\left[Y^{(4 n-1)}=O_{3}\right]_{B}^{M_{2}}=\left[(1-q)(1-p) L_{1}^{3 n-2} L_{2}^{3 n} \cdot\left(1-p_{A}\right)^{2 n-1}\right] \\
& P\left[Y^{(4 n-1)}=O_{4}\right]_{B}^{M_{2}}=\left[(1-q) p L_{1}^{3 n} L_{2}^{3 n-2}\left(1-p_{A}\right)^{2 n-1}\right]
\end{aligned}
$$

Type C: When $t=4 n$

$$
\begin{aligned}
& P\left[Y^{(4 n)}=O_{3}\right]_{C}^{M_{2}}=\left[(1-q) p L_{1}^{3 n} L_{2}^{3 n}\left(1-p_{A}\right)^{2 n}\right] \\
& P\left[Y^{(4 n)}=O_{4}\right]_{C}^{M_{2}}=\left[(1-q)(1-p) L_{1}^{3 n} L_{2}^{3 n}\left(1-p_{A}\right)^{2 n}\right]
\end{aligned}
$$

Type D: When $t=4 n-2$

$$
\begin{aligned}
& P\left[Y^{(4 n-2)}=O_{3}\right]_{D}^{M_{2}}=\left[(1-q)(1-p) L_{1}^{3 n-3} L_{2}^{3 n}\left(1-p_{A}\right)^{2 n-1}\right] \\
& P\left[Y^{(4 n-2)}=O_{4}\right]_{D}^{M_{2}}=\left[(1-q) p L_{1}^{3 n} L_{2}^{3 n-3}\left(1-p_{A}\right)^{2 n-1}\right]
\end{aligned}
$$

\section{TRAFFIC SHARING \& CALL CONNECTION}

The traffic is shared between $0_{\mathrm{i}}(i=1,3)$ and $0_{\mathrm{j}}(j=2,4)$ operators. The aim is to calculate the probability of completion of a call with the assumption that it is achieved at $\mathrm{n}^{\text {th }}$ attempt with operator $\mathrm{O}_{\mathrm{i}}(i=1,3)$ in market-I.

$\overline{\mathrm{P}}_{1}^{n}=\mathrm{P}\left(\right.$ call completes in $n^{\text {th }}$ attempt with operator $\left.O_{1}\right)$.

$P$ (user is at $z$ at $n^{\text {th }}$ attempt when he was at $O_{1}$ in $(n-1)^{\text {th }}$ attempt)

$$
\begin{aligned}
\overline{\mathrm{P}}_{1}^{n} & =\mathrm{P}\left[Y^{n-1}=O_{1}\right] \cdot \mathrm{P}\left[Y^{n}=Z_{1} / Y^{n-1}=O_{1}\right] \\
{\overline{\mathrm{P}_{1}}}^{n} & =\sum_{i=1}^{n} P_{1}{ }^{(i)}=\sum_{i=1}^{n} P\left[Y^{i-1}=O_{1}\right] \cdot \mathrm{P}\left[Y^{i}=Z_{1} / Y^{i-1}=O_{1}\right] \\
\overline{\mathrm{P}}_{1}^{n} & =\left\{1-\left(L_{1}+L_{1}^{2}\right)\right\} \cdot \sum_{i=1}^{n} P\left[Y^{i-1}=O_{1}\right] \\
\overline{\mathrm{P}}_{1} & =\left\{1-\left(L_{1}+L_{1}^{2}\right)\right\}
\end{aligned}
$$




$$
\left[\begin{array}{c}
\sum_{\substack{\mathrm{i}=1 \\
\mathrm{i}=\text { Type A }}}^{n-1} P\left[Y^{i}=O_{1}\right]+\sum_{\substack{\mathrm{i}=1 \\
\mathrm{i}=\text { Type B }}}^{n-1} P\left[Y^{i}=O_{1}\right] \\
\sum_{\substack{\mathrm{i}=1 \\
\mathrm{i}=\text { Type C } \\
\text { C.i=1 }}}^{n-1} P\left[Y^{i}=O_{1}\right]+ \\
\sum_{\mathrm{i}=\text { Type D }}^{n-1} P\left[Y^{i}=O_{1}\right]
\end{array}\right]
$$

$\left[\overline{\mathrm{P}}_{1}\right]_{\text {Type C }}^{M_{1}}=\frac{\left[q p\left\{1-\left(L_{1}+L_{1}^{2}\right)\right\}\right]}{1-L_{1}^{3} L_{2}^{3}\left(1-p_{A}\right)^{2}}$

Similarly can be derived for operator $\mathrm{O}_{2}, \mathrm{O}_{3} \& \mathrm{O}_{4}$ for Market I \& Market -II respectively.

\section{COMPUTATION OF TRAFFIC}

\section{SHARE OVER LARGE NUMBER OF}

\section{ATTEMPTS}

Suppose the number of call attempts made by user is very large and then define

$$
\overline{\mathrm{P}_{1}}=\lim _{n \rightarrow \infty} \overline{\mathrm{P}}_{l}^{n} ; i=1,3 \quad \& \overline{\mathrm{P}}_{2}={ }_{n \rightarrow \infty} \lim _{\mathrm{\textrm {P }}}^{n} ; j=2,4
$$

for Market-I and Market-II respectively, which provides a measure of traffic share between these operators in term of two-call based prospect. The limiting value of the expressions of this section relates to traffic shares.

\subsection{TRAFFIC SHARE EXPRESSION FOR \\ MARKET-I}

$\left[\overline{\mathrm{P}}_{1}\right]_{\mathrm{M}_{1}}=\frac{\left[\mathrm{q}\left(1-\mathrm{L}_{1}\right)\left\{1-\left(\mathrm{L}_{1}+\mathrm{L}_{1}^{2}\right)\right\}\left\{\mathrm{p}+(1-\mathrm{p}) \mathrm{L}_{2}^{3}\left(1-\mathrm{p}_{\mathrm{A}}\right)\right\}\right]}{1-\mathrm{L}_{1}^{3} \mathrm{~L}_{2}^{3}\left(1-\mathrm{p}_{\mathrm{A}}\right)^{2}}$

$\left[\overline{\mathrm{P}_{2}}\right]_{\mathrm{M}_{1}}=\frac{\left[\mathrm{q}\left(1-\mathrm{L}_{2}\right)\left\{1-\left(\mathrm{L}_{2}+\mathrm{L}_{2}^{2}\right)\right\}\left\{(1-\mathrm{p})+\mathrm{pL}_{1}^{3}\left(1-\mathrm{p}_{\mathrm{A}}\right)\right\}\right]}{1-\mathrm{L}_{1}^{3} \mathrm{~L}_{2}^{3}\left(1-\mathrm{p}_{\mathrm{A}}\right)^{2}}$

Now we again separate traffic share expression in the following forms:

$\left[\overline{\mathrm{P}}_{1}\right]_{\text {Type A }}^{M_{1}}=\frac{\left[q p L_{1}\left\{1-\left(L_{1}+L_{1}^{2}\right)\right\}\right]}{1-L_{1}^{3} L_{2}^{3}\left(1-p_{A}\right)^{2}}$

$\left[\overline{\mathrm{P}}_{2}\right]_{\text {Type A }}^{M_{1}}=\frac{\left[q(1-p) L_{2}\left\{1-\left(L_{2}+L_{2}^{2}\right)\right\}\right]}{1-L_{1}^{3} L_{2}^{3}\left(1-p_{A}\right)^{2}}$

$\left[\overline{\mathrm{P}}_{1}\right]_{\text {Type B }}^{M_{1}}=\frac{\left[q(1-p) L_{1} L_{2}^{3}\left(1-p_{A}\right)\left\{1-\left(L_{1}+L_{1}^{2}\right)\right\}\right]}{1-L_{1}^{3} L_{2}^{3}\left(1-p_{A}\right)^{2}}$

$\left[\overline{\mathrm{P}}_{2}\right]_{\text {Type B }}^{M_{1}}=\frac{\left[q p L_{1}^{3} L_{2}\left(1-p_{A}\right)\left\{1-\left(L_{2}+L_{2}^{2}\right)\right\}\right]}{1-L_{1}^{3} L_{2}^{3}\left(1-p_{A}\right)^{2}}$
$\left[\overline{\mathrm{P}}_{2}\right]_{\text {Type } C}^{M_{1}}=\frac{\left[q(1-p)\left\{1-\left(L_{2}+L_{2}^{2}\right)\right\}\right]}{1-L_{1}^{3} L_{2}^{3}\left(1-p_{A}\right)^{2}}$

$$
\left[\overline{\mathrm{P}}_{1}\right]_{\text {Type } D}^{M_{1}}=\frac{\left[q(1-p) L_{2}^{3}\left(1-p_{A}\right)\left\{1-\left(L_{1}+L_{1}^{2}\right)\right\}\right]}{1-L_{1}^{3} L_{2}^{3}\left(1-p_{A}\right)^{2}}
$$

$\left[\overline{\mathrm{P}}_{2}\right]_{\text {Type D }}^{M_{1}}=\frac{\left[q p L_{1}^{3}\left(1-p_{A}\right)\left\{1-\left(L_{2}+L_{2}^{2}\right)\right\}\right]}{1-L_{1}^{3} L_{2}^{3}\left(1-p_{A}\right)^{2}}$

\subsection{TRAFFIC SHARE EXPRESSION FOR MARKET- II}

$\left[\overline{\mathrm{P}}_{1}\right]_{\mathrm{M}_{2}}=\frac{\left[(1-\mathrm{q})\left(1-\mathrm{L}_{1}\right)\left\{1-\left(\mathrm{L}_{1}+\mathrm{L}_{1}^{2}\right)\right\}\left\{\mathrm{p}+(1-\mathrm{p}) \mathrm{L}_{2}^{3}\left(1-\mathrm{p}_{\mathrm{A}}\right)\right\}\right]}{1-\mathrm{L}_{1}^{3} \mathrm{~L}_{2}^{3}\left(1-\mathrm{p}_{\mathrm{A}}\right)^{2}}$

$\left[\overline{\mathrm{P}_{2}}\right]_{\mathrm{M}_{2}}=\frac{\left[(1-\mathrm{q})\left(1-\mathrm{L}_{2}\right)\left\{1-\left(\mathrm{L}_{2}+\mathrm{L}_{2}^{2}\right)\right\}\left\{(1-\mathrm{p})+\mathrm{pL}_{1}^{3}\left(1-\mathrm{p}_{\mathrm{A}}\right)\right\}\right]}{1-\mathrm{L}_{1}^{3} \mathrm{~L}_{2}^{3}\left(1-\mathrm{p}_{\mathrm{A}}\right)^{2}}$

Now we again separate traffic share expression in the following forms:

$\left[\overline{\mathrm{P}}_{1}\right]_{\text {Type A }}^{M_{2}}=\frac{\left[(1-q) p L_{1}\left\{1-\left(L_{1}+L_{1}^{2}\right)\right\}\right]}{1-L_{1}^{3} L_{2}^{3}\left(1-p_{A}\right)^{2}}$

$\left[\overline{\mathrm{P}}_{2}\right]_{\text {Type A }}^{M_{2}}=\frac{\left[(1-q)(1-p) L_{2}\left\{1-\left(L_{2}+L_{2}^{2}\right)\right\}\right]}{1-L_{1}^{3} L_{2}^{3}\left(1-p_{A}\right)^{2}}$

$\left[\overline{\mathrm{P}}_{1}\right]_{\text {Type B }}^{M_{2}}=\frac{\left[(1-q)(1-p) L_{1} L_{2}^{3}\left(1-p_{A}\right)\left\{1-\left(L_{1}+L_{1}^{2}\right)\right\}\right]}{1-L_{1}^{3} L_{2}^{3}\left(1-p_{A}\right)^{2}}$

$\left[\overline{\mathrm{P}}_{2}\right]_{\text {Type B }}^{M_{2}}=\frac{\left[(1-q) p L_{1}^{3} L_{2}\left(1-p_{A}\right)\left\{1-\left(L_{2}+L_{2}^{2}\right)\right\}\right]}{1-L_{1}^{3} L_{2}^{3}\left(1-p_{A}\right)^{2}}$

$\left[\overline{\mathrm{P}}_{1}\right]_{\text {Type C }}^{M_{2}}=\frac{\left[(1-q) p\left\{1-\left(L_{1}+L_{1}^{2}\right)\right\}\right]}{1-L_{1}^{3} L_{2}^{3}\left(1-p_{A}\right)^{2}}$ 
$\left[\overline{\mathrm{P}}_{2}\right]_{\text {Type } C}^{M_{2}}=\frac{\left[(1-q)(1-p)\left\{1-\left(L_{2}+L_{2}^{2}\right)\right\}\right]}{1-L_{1}^{3} L_{2}^{3}\left(1-p_{A}\right)^{2}}$

$\left[\overline{\mathrm{P}}_{1}\right]_{\text {Type D }}^{M_{2}}=\frac{\left[(1-q)(1-p) L_{2}^{3}\left(1-p_{A}\right)\left\{1-\left(L_{1}+L_{1}^{2}\right)\right\}\right]}{1-L_{1}^{3} L_{2}^{3}\left(1-p_{A}\right)^{2}}$

$\left[\overline{\mathrm{P}}_{2}\right]_{\text {Type D }}^{M_{2}}=\frac{\left[(1-q) p L_{1}^{3}\left(1-p_{A}\right)\left\{1-\left(L_{2}+L_{2}^{2}\right)\right\}\right]}{1-L_{1}^{3} L_{2}^{3}\left(1-p_{A}\right)^{2}}$

\section{SIMULATION STUDY}

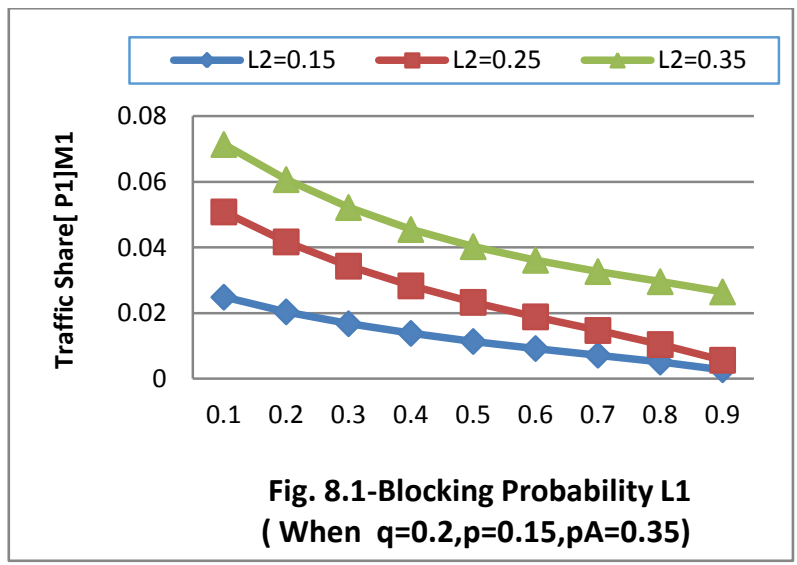

In view of figure 8.1 , it is observe that when $q=20 \%, p=15 \%$ and probability of abandon $p_{A}=35 \%$ traffic share pattern of operator $O_{1}$ in market-I is downward trend, subject to the condition for little increment of opponent block $L_{2}$ by $10 \%$.

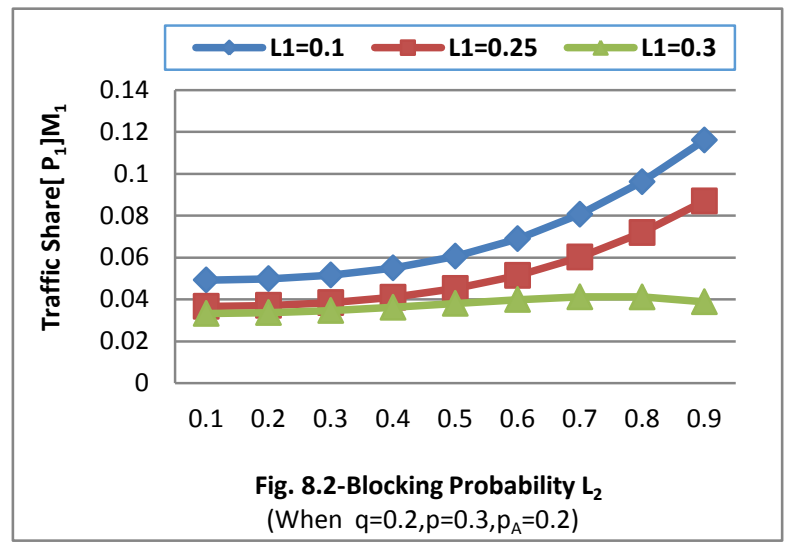

In light of figure 8.2 , cubic form of traffic share has been found for some constant parameter $\mathrm{q}=20 \%, \mathrm{p}=30 \%$ and $p_{A}=$ $20 \%$ and with constant increment in networking blocking probability $L_{1}$.

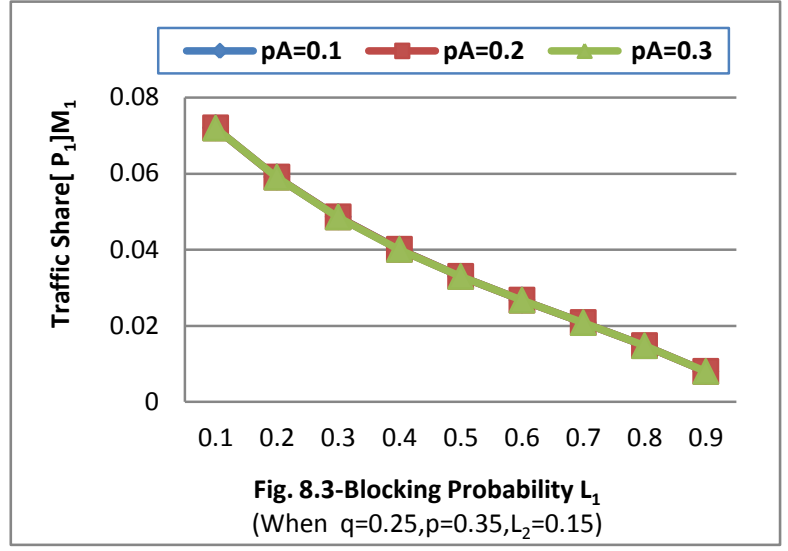

Looking over figure 8.3, traffic share patterns are overlapped subject to fixed increment in abandon probability $p_{A}$ by $10 \%$ and when opponent blocking $L_{2}=15 \%, \mathrm{p}=35 \%$ and $\mathrm{q}=25 \%$.
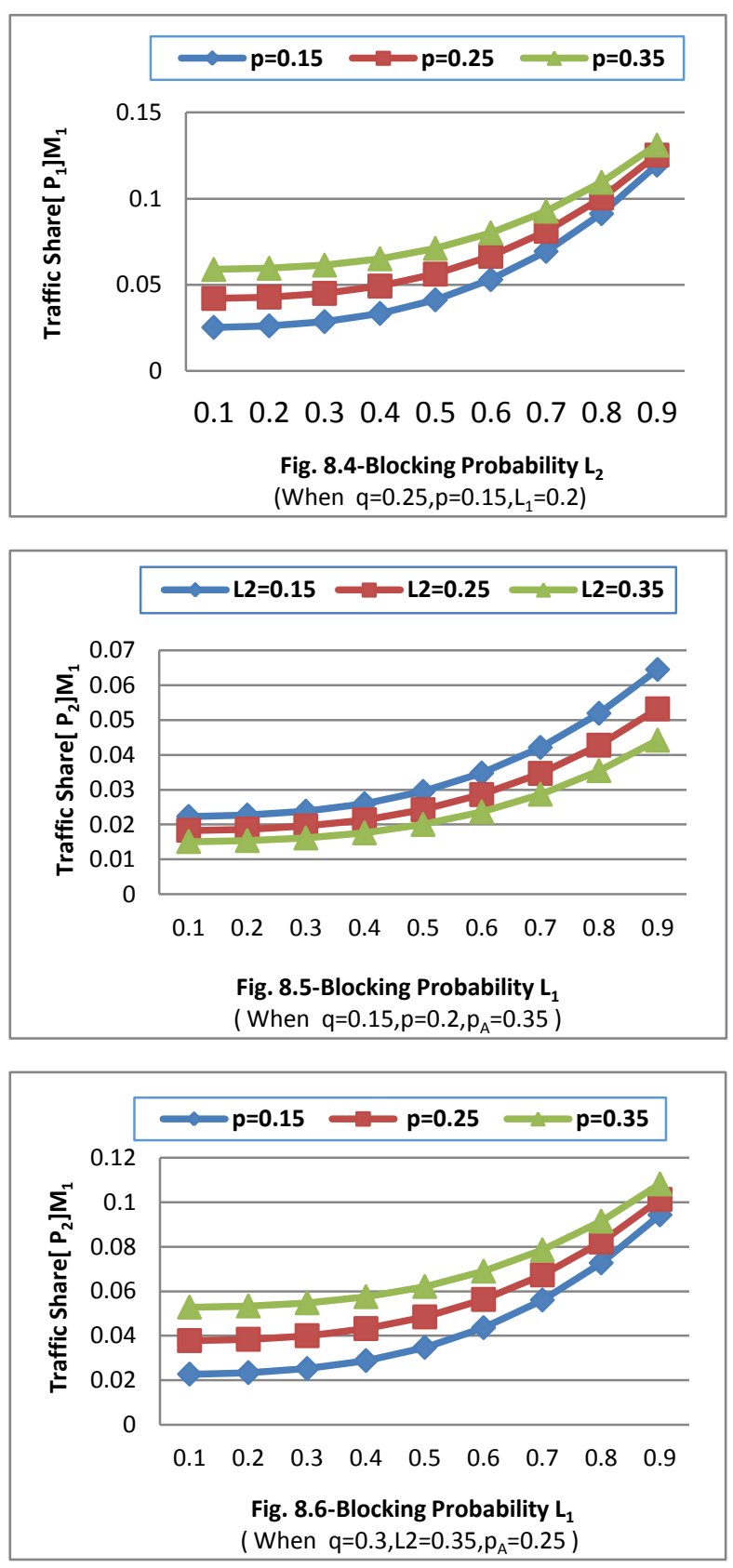
With reference to figure number 8.4 to 8.6 , a similar pattern was found with the different variation in network parameters. Overall upward trend of traffic share was seen.

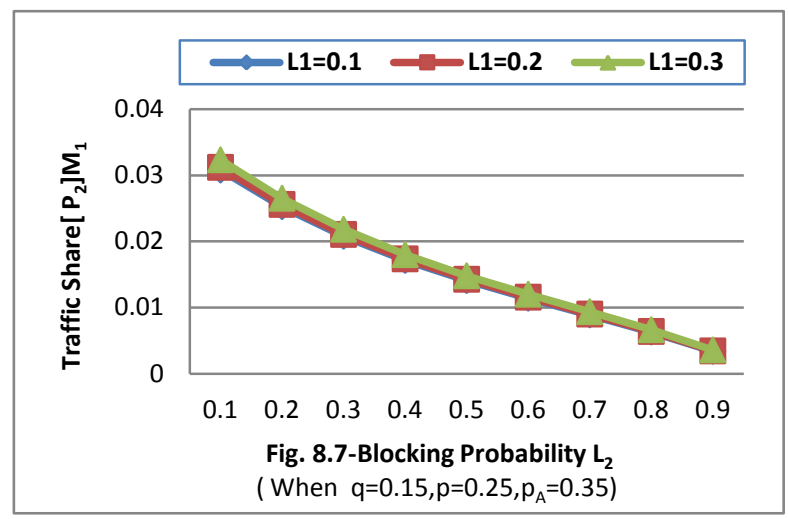

In figure 8.7 it is found that in market-I similar pattern was seen as fig. 3 for operator $\mathrm{O}_{2}$ at different stage of variant parameters.

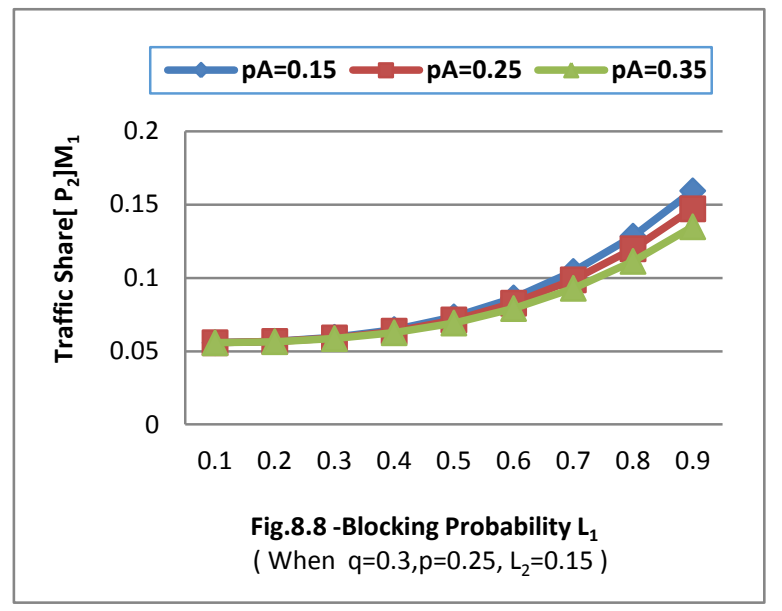

Figure 8.8 depicts the fact that little increment of abandon probability $p_{A}$ by $10 \%$ traffic share pattern is in cubic form with respect to block probability $L_{1}$ and fixed parameter $\mathrm{p}=$ $25 \%, \mathrm{q}=30 \%$ and opponent blocking $L_{2}=15 \%$.

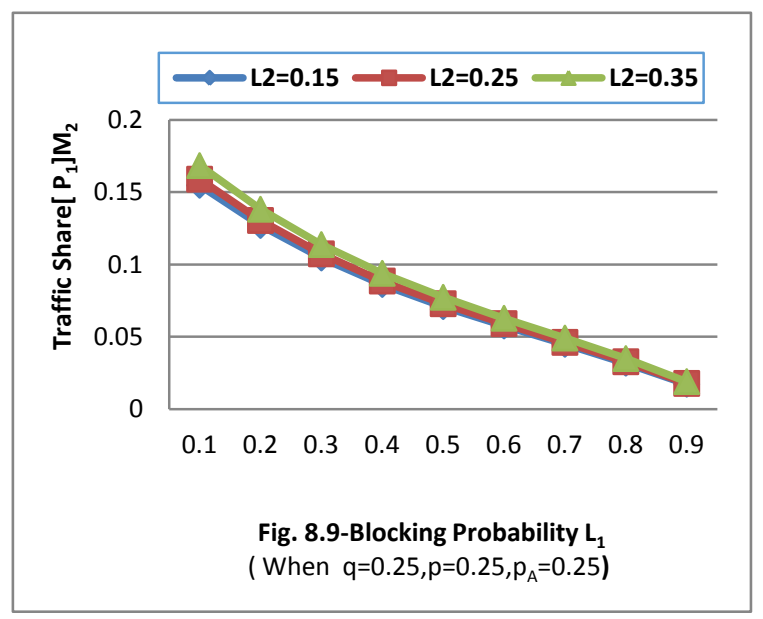

Figure 8.9 shows that graph pattern is downward from $16 \%$ to nearly $1 \%$ in market II.
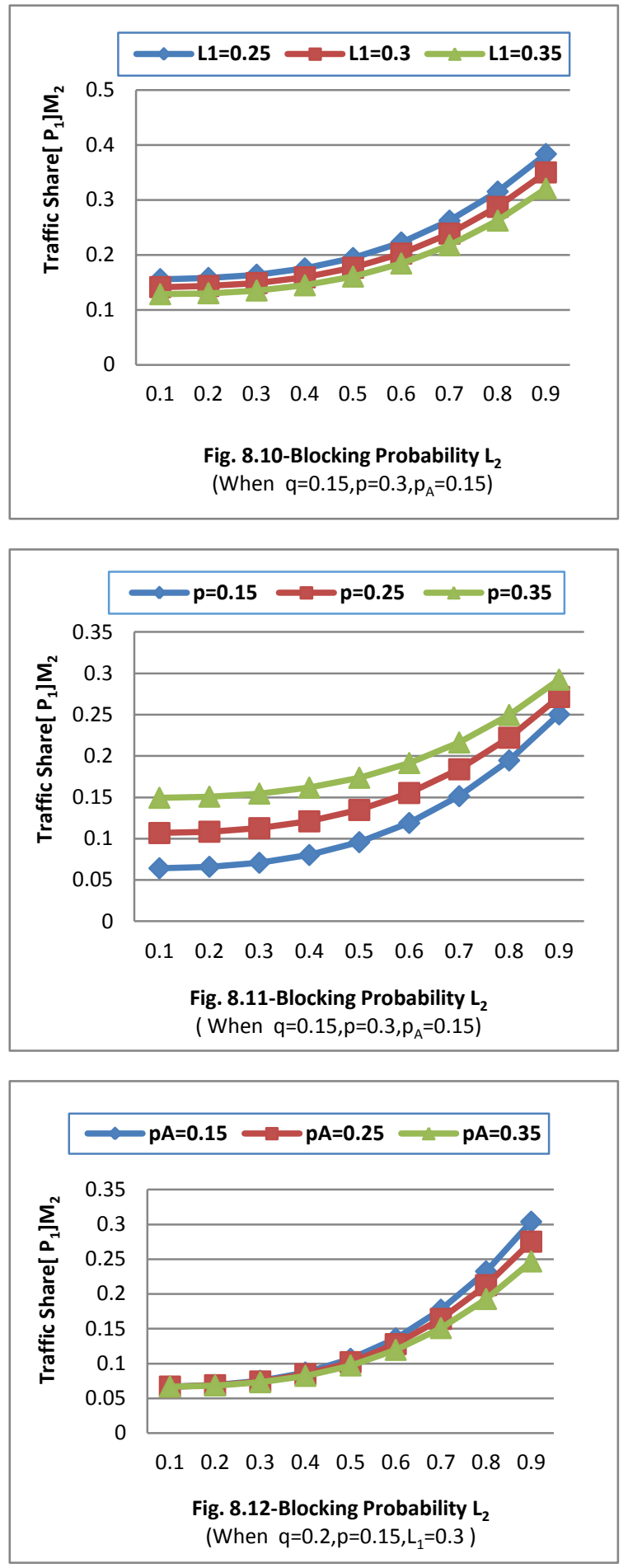

In reference from figure 8.10 to figure 8.12 traffic share patterns are upward with respect to blocking probability $L_{2}$ with some constant increment in $L_{1}$, blocking probability $L_{2}$ with little increment of initial choice $\mathrm{p}$ and blocking probability $L_{2}$ for some fixed network parameter $p_{A}$ respectively. In the above graph, maximum $40 \%$ traffic share was found in various network parameters. 


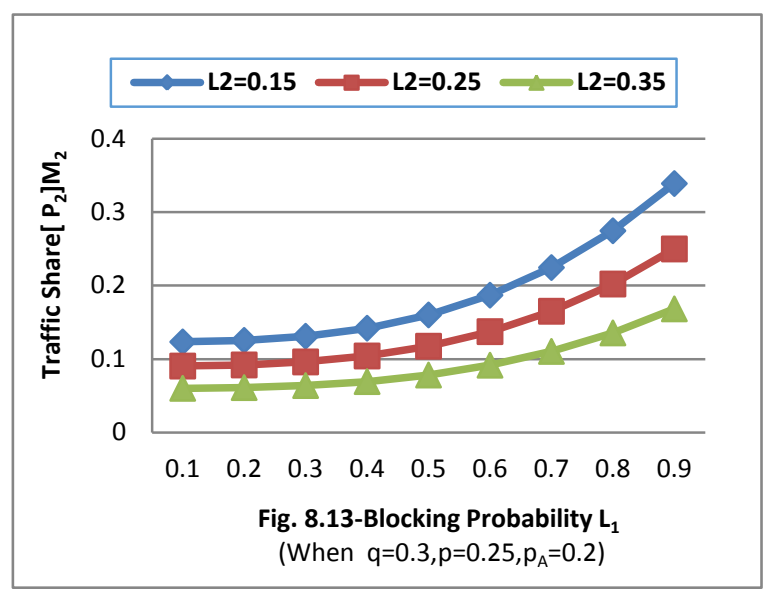

Figure 8.13 reflects that for market-II traffic share pattern increases with respect to blocking probability $L_{1}$ and fixed network parameter $\mathrm{q}=30 \%, \mathrm{p}=25 \%$ and $p_{A}=20 \%$ with the condition when opponent blocking increase $10 \%$ respectively.

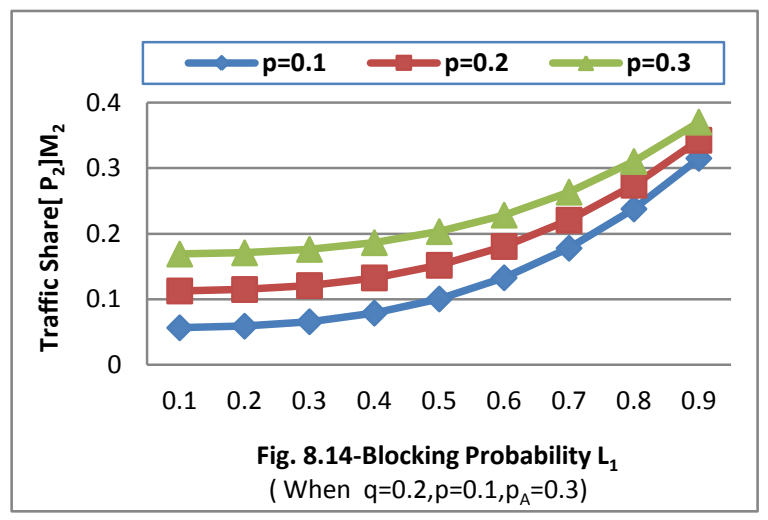

Figure 8.14 shows that increasing pattern of traffic share is more as compare to figure 13 with some incremental growth by initial probability p by $10 \%$ and for constant value of $q=$ $20 \%, \mathrm{p}=10 \%$ and $p_{A}=30 \%$.

\section{CONCLUSION}

Utility of markov chain model is quite effective for understanding the transition behaviour of users in two market based setup. At different stages of network blocking, many interesting results have been seen. Traffic share pattern are overlapped in the case when $\mathrm{q}=25 \%, \mathrm{p}=35 \%, \mathrm{p}_{\mathrm{A}}=15 \%$ and $\mathrm{q}=15 \%, \mathrm{p}=25 \%, \mathrm{p}_{\mathrm{A}}=35 \%$. At the same time in some cases traffic share patterns are in cubic form When $q=30 \%, \mathrm{~L}_{2}=$ $35 \%$ and $\mathrm{p}_{\mathrm{A}}=25 \%$. Moreover by the analysis of both markets it is found that the traffic share depends on market position. If market is of high priority then blocking probability of service provider is much higher as compare to competitive service provider in two-call-based setup.

\section{REFERENCES}

[1] K. Park, W. Willinger, "Self-Similar Network Traffic and Performance Evaluation", New York: John Wiley \& Sons Inc., 2000

[2] M. Naldi, "Internet Access Traffic Sharing in A Multiuser Environment", Computer Networks, 38(6):809824,2002

[3] D. Shukla and Gadewar, S.,"Stochastic Model for Cell Movement in a Knockout Switch in Computer
Networks", Journal of High S peed Network, 16(3):310332,2007

[4] J. Medhi, "Stochastic Processes", Ed. 4, Wiley Eastern Limited (Fourth reprint), New Delhi ,1992

[5] Shukla, D. Gadewar, S. Pathak, R.K. "A Stochastic Model for Space-Division Switches in Computer Networks", Applied Mathematics and Computation (Elsevier Journal), 184(2):235-269, 2007

[6] Altman, E., Avrachenkov, A. and Brakat, C., "TCP Network Calculus: The Case of Large Delay-Bandwidth Product", IEEE Conference on Computer Communications, 21(1):417-426,2002

[7] Antal, C., Molnar, S. and Szabo, G.,"Performance Study of Distributed Channel Allocation Techniques For a Fast Circuit Switched Network", Computer Communications, 21(17):1587-1609,1998

[8] M. Newby and R. Dagg, "Optical inspection and maintenance for stochastically deteriorating systems, average cost criteria", Jour. Ind. Stat. Asso.,40(2):169198,2002

[9] Agarwal, Rinkle and Kaur, Lakhwinder, "On Reliability Analysis of Fault-Tolerant Multistage Interconnection Networks", International Journal of Computer Science and Security (IJCSS),2(4):1-8,2008

[10] Catledge, L. D. and Pitkow J.E., "Characterizing browsing strategies in the World Wide Web", Computer Networks and ISDN Systems,27 (6):1065-1073,1995

[11] Tiwari, Virendra, Thakur, Sanjay and Shukla, D.,"Cyber Crime Analysis For Multi-Dimensional Effect In Computer Network", Journal of Global Research in Computer Science,1(4): 31-37,2010

[12] M. Naldi, "Measurement based modelling of Internet Dial-up Access Connections ",Computer Networks,31(22):2381-2390,1999

[13] Shukla, D., Thakur, Sanjay,"State Probability Analysis of Users in Internet between Two Operators", International Journal of Advanced Networking and Applications (IJANA),1(2):90-95,2009

[14] Shukla, D.,Gadewar, S. Pathak, R.K., "A Stochastic Model for Space-Division Switches in Computer Networks",Applied Mathematics and Computation (Elsevier Journal),184(2):235-269,2007

[15] Shukla, D.,Gadewar, "Stochastic Model for Internet Traffic Sharing", National conference on research and development trend in ICT,pp.222-244,13 Feb 2010

[16] Shukla, D. and Singhai, Rahul, "Analysis Of User Web Browsing Behaviour Using Markov Chain Model", International Journal of Advanced Networking and Application (IJANA),2(5):824-830,2011

[17] Shukla, D.,Gangele, Sharad, Singhai, R., Verma, Kapil, "Elasticity Analysis of Web-Browsing Behaviour of Users, International Journal of Advanced Networking and Application(IJANA), 3(3):1162-1168,2011

[18] Shukla, D., Verma, Kapil and Gangele, Sharad,“Curve Fitting Approximation In Internet Traffic Distribution In Computer Network In Two Market Environment", 
International Journal of Computer Science and Information Security (IJCSIS),10(5):71-78,2012

[19] Gangele,Sharad, Shukla,D., "Area Computation of Internet Traffic Share Problem With Special Reference to Cyber Crime Environment", International Journal of Computer Networks and Wireless Communication, 4(3):208-219, 2014

[20] Gangele,Sharad,Dongre,Ashish, "Probability Density Estimation Function of Browser Share Curve for Users Web Browser Behaviour, International Journal of Engineering Research and Development,10(6):31-41, 2014

[21] Gangele, Sharad, Dongre,Ashish, "Two-call index based internet traffic sharing analysis in case of cyber crime environment of computer network", International Journal of Engineering Trend and Technology,13(6):271-280, 2014
[22] Gangele, Sharad,"An Approach for Area Estimation towards Conjunction Control of Internet Traffic Sharing by Using Simpson 1/3ed Rule", International Journal of Engineering Trend and Technology, 16(2):88-99,2014

[23] Shukla, D., Verma, Kapil and Gangele, Sharad, "Approximating the Probability of Traffic Sharing by Numerical Analysis Techniques between Two Operators in a Computer Network", American Journal of Computer Science and Information Technology,3(1):26-39,2015

[24] Shukla, D., Verma, Kapil and Gangele, Sharad, "Bounded Area Estimation Using Simpson 3/8 Rule in Traffic Share Scenario in Computer Network" International Journal of Computer And Communication System Engineering ,1(4):119-125,2015 